\title{
Survival benefits of adding simvastatin to standard therapy for secondary prevention of bleeding esophageal varices in patients with hepatitis C-related liver cirrhosis
}

Helmy Elshazly ${ }^{1}$, Hasan Zaghlah' ${ }^{1}$, El-Sayed Tharwa ${ }^{1}$, Ahmed Abuamer ${ }^{1}$, Dina Nor-Eldin², Reem El Sheemy ${ }^{3}$ and Mohamed El Kassas ${ }^{4^{*}}$ (i)

\begin{abstract}
Background: The combination of endoscopic band ligation and beta-blockers is the standard of care treatment for secondary prevention of variceal bleeding; however, rebleeding still occurs with associated high mortality. Simvastatin (a lipid-lowering agent) was found to reduce portal hypertension and decrease hepatic fibrosis. This study aimed to assess the effect of adding simvastatin to the standard therapy to prevent variceal rebleeding and its impact on survival in patients with liver cirrhosis.

Results: This single-center randomized controlled clinical trial included 80 patients with cirrhosis receiving the standard secondary prophylaxis for variceal bleeding composed of endoscopic variceal ligation and non-selective $\beta$ blockers (either propranolol or carvedilol). Two weeks after the first attack of hematemesis, patients were randomized into two groups: group I who received the standard therapy (40 patients) and group II who administered simvastatin (20 mg daily for 2 weeks and $40 \mathrm{mg}$ daily after that). Patients were followed up for 1 year. The primary endpoints were rebleeding and overall survival. Thirty patients of group I completed the study while ten patients died during the follow-up period. The simvastatin group showed a significantly better overall 1-year survival (3 deaths during follow-up) compared to the control group (37/40, 92.5\% vs. 30/40; 75\%) ( $p$-value 0.034); however, this was lacking in Child $\mathrm{C}$ patients. No similar difference was present in rebleeding rates between the two groups (5/40, $12.5 \%$ vs. $3 / 40,7.5 \%$ ) ( $p$-value 0.456 ) in groups I and II, respectively.

Conclusions: Adding simvastatin to the standard therapy in secondary prevention of variceal bleeding could be associated with survival benefits in patients with Child A and B cirrhosis, while was incapable of reducing rebleeding.
\end{abstract}

Keywords: Bleeding varices, Beta-blockers, Egypt, Hematemesis, Cirrhosis, Secondary prevention, Simvastatin, Statins, Portal hypertension, Prophylaxis

\footnotetext{
* Correspondence: m_elkassas@yahoo.com

${ }^{4}$ Endemic Medicine Department, Faculty of Medicine, Helwan University, Ain Helwan, Cairo 11795, Egypt

Full list of author information is available at the end of the article
}

\section{Springer Open}

(c) The Author(s). 2021 Open Access This article is licensed under a Creative Commons Attribution 4.0 International License, which permits use, sharing, adaptation, distribution and reproduction in any medium or format, as long as you give appropriate credit to the original author(s) and the source, provide a link to the Creative Commons licence, and indicate if changes were made. The images or other third party material in this article are included in the article's Creative Commons licence, unless indicated otherwise in a credit line to the material. If material is not included in the article's Creative Commons licence and your intended use is not permitted by statutory regulation or exceeds the permitted use, you will need to obtain permission directly from the copyright holder. To view a copy of this licence, visit http://creativecommons.org/licenses/by/4.0/. 


\section{Background}

Liver cirrhosis is considered the most common cause of portal hypertension (PHT) [1]. Increased portal inflow and increased outflow resistance are associated with the development of PHT [2]. Liver transplantation is indicated in patients with advanced cirrhosis complicated by PHT; furthermore, morbidity and mortality are augmented in these patients $[3,4]$. PHT management's ideal drug should decrease portal pressure by lowering intrahepatic vascular resistance while maintaining or increasing hepatic blood flow [3]. Moreover, it should improve liver function through its antifibrotic effects, and it should be able to increase nitric oxide bioavailability in the liver to help fulfill many of these requirements [3, 58]. Currently, the available therapies for PHT are based on the use of $\beta$-adrenergic blockers, with or without organic nitrates, and allow achievement of the target hemodynamic response in less than half of patients.

Moreover, about $30 \%$ of patients may have contraindications or may not tolerate $\beta$-blockers [9]. Statins such as simvastatin are used mainly for cardiovascular diseases and metabolic syndrome. They exert multiple pleiotropic effects and can be used safely in patients with chronic liver diseases [10]. Statins can have antiinflammatory and antifibrotic effects in patients with liver cirrhosis through many proposed mechanisms [1114]. Some reports showed survival benefits and improvement in liver profile with simvastatin use $[14,15]$. Moreover, an improvement in PHT, reduction in hepatocellular carcinoma (HCC) incidence, and delays in hepatic decompensation have been associated with the use of statins in patients with liver cirrhosis $[15,16]$.

We aimed to assess the effect of adding simvastatin to the standard therapy used to prevent variceal rebleeding and to evaluate its impact on survival in patients with HCV-related liver cirrhosis. Statins have a long history of being safe and tolerable medications. Because this family of drugs is generic and inexpensive, there will be few barriers to general acceptance of statins' role in preventing bleeding in patients with esophageal varices if the theory is validated.

\section{Methods}

This prospective single-center randomized control study was conducted in the National Liver Institute Hospital, Menoufia, Egypt, between June 2017 and January 2019. The target population of this study was patients with cirrhosis as diagnosed by abdominal ultrasonography and furtherly confirmed and stratified by the Child-TurcottePugh score (CTP score), who recovered from the first attack of variceal bleeding. The sample size and power analysis were calculated using the Epi-Info software statistical package created by the World Health Organization and Center for Disease Control and Prevention, Atlanta, GA, USA, version 2002. The criteria used for sample size calculations were $95 \%$ confidence limit and $80 \%$ power of the study. The sample size was estimated as 40 subjects in each study group, with a total sample size of 80 participants.

Within 2 weeks of the index hematemesis episode, patients were randomized into two groups (by using closed envelops) that was previously generated with a specialized software:

Group 1 (control group) included 40 patients who received the standard secondary prophylaxis of variceal bleeding composed of endoscopic variceal band ligation and non-selective $\beta$-blockers (NSBB): either propranolol or carvedilol.

Group 2 included 40 patients who received simvastatin in addition to the previous standard secondary prophylaxis of variceal bleeding. Simvastatin was given in a dose of $20 \mathrm{mg}$ daily for 2 weeks and $40 \mathrm{mg}$ daily after that.

The inclusion criteria were age between 18 and 80 years, evidence of liver cirrhosis, and first attack of variceal bleeding within the previous 2 weeks. The exclusion criteria included pregnancy or lactation, hepatocellular

Table 1 Baseline characteristics in both groups

\begin{tabular}{|c|c|c|c|c|c|c|}
\hline & & & Range & Mean \pm S.D & $t$ test & $p$-value \\
\hline \multirow[t]{2}{*}{ Age } & & Group I & $33-63$ & $47.48 \pm 7.36$ & 0.030 & 0.863 \\
\hline & & Group II & $33-65$ & $47.75 \pm 6.82$ & & \\
\hline Sex & & & Group I & Group II & Total & \\
\hline \multirow[t]{2}{*}{ Male } & & $N$ & 22 & 30 & 52 & \\
\hline & & $\%$ & $55.0 \%$ & $75.0 \%$ & $65.0 \%$ & \\
\hline \multirow[t]{2}{*}{ Female } & & $N$ & 18 & 10 & 28 & \\
\hline & & $\%$ & $45.0 \%$ & $25.0 \%$ & $35.0 \%$ & \\
\hline \multirow[t]{2}{*}{ Total } & & $N$ & 40 & 40 & 80 & \\
\hline & & $\%$ & $100.0 \%$ & $100.0 \%$ & $100.0 \%$ & \\
\hline \multirow[t]{2}{*}{ Chi-square } & $x^{2}$ & 3.516 & & & & \\
\hline & $p$-value & 0.0610 .061 & & & & \\
\hline
\end{tabular}


carcinoma, creatinine above $2 \mathrm{mg} / \mathrm{dL}$, CTP score $>13$, contraindication for statins, previous portosystemic shunt, bleeding gastric varices, thrombosed portal vein or portal vein malformations, previous treatment with the standard of care prophylaxis (before the index episode), and previous exposure to statins within 1 month of randomization.

All recruited patients received the standard secondary prophylaxis of variceal bleeding (endoscopic variceal band ligation and NSBB). Medical prophylaxis (NSBB) started after a week of the index hematemesis episode, with either propranolol or carvedilol. Doses of NSBB were increased gradually to the maximum tolerated dose. After having the initial endoscopic band ligation session, scheduled endoscopic follow-up was arranged 2 to 4 weeks after and repeated until reporting variceal eradication. Patients were followed up regularly after 2 weeks of randomization; at months 3,6 , and 9; and at the end of the follow-up year. Other concomitant medications of the study patients were maintained during the follow-up period. Upper GI endoscopy was the standard gold method used in diagnosing and staging gastroesophageal varices (GOVs) (small varices $<5 \mathrm{~mm}$ and large varices $>5 \mathrm{~mm}$ ).

\section{Results}

The current study included 80 patients with cirrhosis and PHT (40 in each group). Regarding the cause of cirrhosis, 77 patients were hepatitis $\mathrm{C}$ virus ( $\mathrm{HCV}$ )-positive, two were hepatitis B virus (HBV)-positive, and one had combined HCV and HBV infections. There was no statistically significant difference between the two groups regarding age, sex, clinical features, and medical history (hypertension, diabetes mellitus, and diuretics therapy history). Baseline characteristics in both groups are detailed in Table 1.

Also, no significant difference was encountered in the CTP score between the two studied groups (Table 2).

Table 2 Comparison of the Child-Pugh score classification of the studied groups

\begin{tabular}{|c|c|c|c|c|c|}
\hline \multicolumn{3}{|l|}{ Child score } & \multirow{2}{*}{$\begin{array}{l}\text { Group I } \\
8\end{array}$} & \multirow{2}{*}{$\begin{array}{l}\text { Group II } \\
9\end{array}$} & \multirow{2}{*}{$\begin{array}{l}\text { Total } \\
17\end{array}$} \\
\hline A & & $N$ & & & \\
\hline & & $\%$ & $20.0 \%$ & $22.5 \%$ & $21.3 \%$ \\
\hline \multirow[t]{2}{*}{ B } & & $N$ & 21 & 19 & 40 \\
\hline & & $\%$ & $52.5 \%$ & $47.5 \%$ & $50.0 \%$ \\
\hline \multirow[t]{2}{*}{ C } & & $N$ & 11 & 12 & 23 \\
\hline & & $\%$ & $27.5 \%$ & $30.0 \%$ & $28.8 \%$ \\
\hline \multirow[t]{2}{*}{ Total } & & $N$ & 40 & 40 & 80 \\
\hline & & $\%$ & $100.0 \%$ & $100.0 \%$ & $100.0 \%$ \\
\hline \multirow[t]{2}{*}{ Chi-square } & $x^{2}$ & 0.202 & & & \\
\hline & $p$-value & 0.904 & & & \\
\hline
\end{tabular}

Table 3 Endoscopic finding of the two studied groups

\begin{tabular}{|c|c|c|c|c|c|c|}
\hline Endoscope & & & Group I & Group II & $x^{2}$ & $p$-value \\
\hline \multirow[t]{6}{*}{15 days } & Grade 2 & $N$ & 21 & 24 & 2.237 & 0.327 \\
\hline & & $\%$ & $52.5 \%$ & $60.0 \%$ & & \\
\hline & Grade 3 & $N$ & 13 & 14 & & \\
\hline & & $\%$ & $32.5 \%$ & $35.0 \%$ & & \\
\hline & Grade 4 & $N$ & 6 & 2 & & \\
\hline & & $\%$ & $15.0 \%$ & $5.0 \%$ & & \\
\hline \multirow[t]{6}{*}{3 months } & Grade 2 & $N$ & 22 & 31 & 5.901 & 0.052 \\
\hline & & $\%$ & $55.0 \%$ & $77.5 \%$ & & \\
\hline & Grade 3 & $N$ & 12 & 8 & & \\
\hline & & $\%$ & $30.0 \%$ & $20.0 \%$ & & \\
\hline & Grade 4 & $N$ & 6 & 1 & & \\
\hline & & $\%$ & $15.0 \%$ & $2.5 \%$ & & \\
\hline \multirow[t]{6}{*}{6 months } & Grade 2 & $N$ & 27 & 33 & 5.667 & 0.059 \\
\hline & & $\%$ & $67.5 \%$ & $82.5 \%$ & & \\
\hline & Grade 3 & $N$ & 8 & 7 & & \\
\hline & & $\%$ & $20.0 \%$ & $17.5 \%$ & & \\
\hline & Grade 4 & $N$ & 5 & 0 & & \\
\hline & & $\%$ & $12.5 \%$ & $.0 \%$ & & \\
\hline \multirow[t]{6}{*}{9 months } & Grade 2 & $N$ & 32 & 35 & 3.134 & 0.209 \\
\hline & & $\%$ & $80.0 \%$ & $87.5 \%$ & & \\
\hline & Grade 3 & $N$ & 5 & 5 & & \\
\hline & & $\%$ & $12.5 \%$ & $12.5 \%$ & & \\
\hline & Grade 4 & $N$ & 3 & 0 & & \\
\hline & & $\%$ & $7.5 \%$ & $.0 \%$ & & \\
\hline \multirow[t]{6}{*}{12 months } & Grade 2 & $N$ & 32 & 35 & 3.134 & 0.209 \\
\hline & & $\%$ & $80.0 \%$ & $87.5 \%$ & & \\
\hline & Grade 3 & $N$ & 5 & 5 & & \\
\hline & & $\%$ & $12.5 \%$ & $12.5 \%$ & & \\
\hline & Grade 4 & $N$ & 3 & 0 & & \\
\hline & & $\%$ & $7.5 \%$ & $0 \%$ & & \\
\hline
\end{tabular}

Also, no statistically significant difference between the two groups was present in baseline laboratory analysis (blood picture indices, liver and kidney function tests, INR). After having the initial endoscopic band ligation session, scheduled endoscopic follow-up was performed at 2-4 weeks after; at months 3,6 , and 9; and at the end of the follow-up year. Detailed follow-up results of the performed endoscopies are reported in Table 3.

Statistically significant survival benefits were observed in the simvastatin group $(37 / 40 ; 92.5 \%)$ as compared to the control group $(30 / 40 ; 75.0 \%)(p$-value $=0.034)$. Upon stratifying the patients according to CTP score, there was a significant difference in survival in patients with CTP A \& B classes $(p<0.05)$, while no survival benefits were found in CTP class C patients, as shown in Fig. 1 . All reported deaths in both groups were linked to events 


\section{Survival of studied groups}

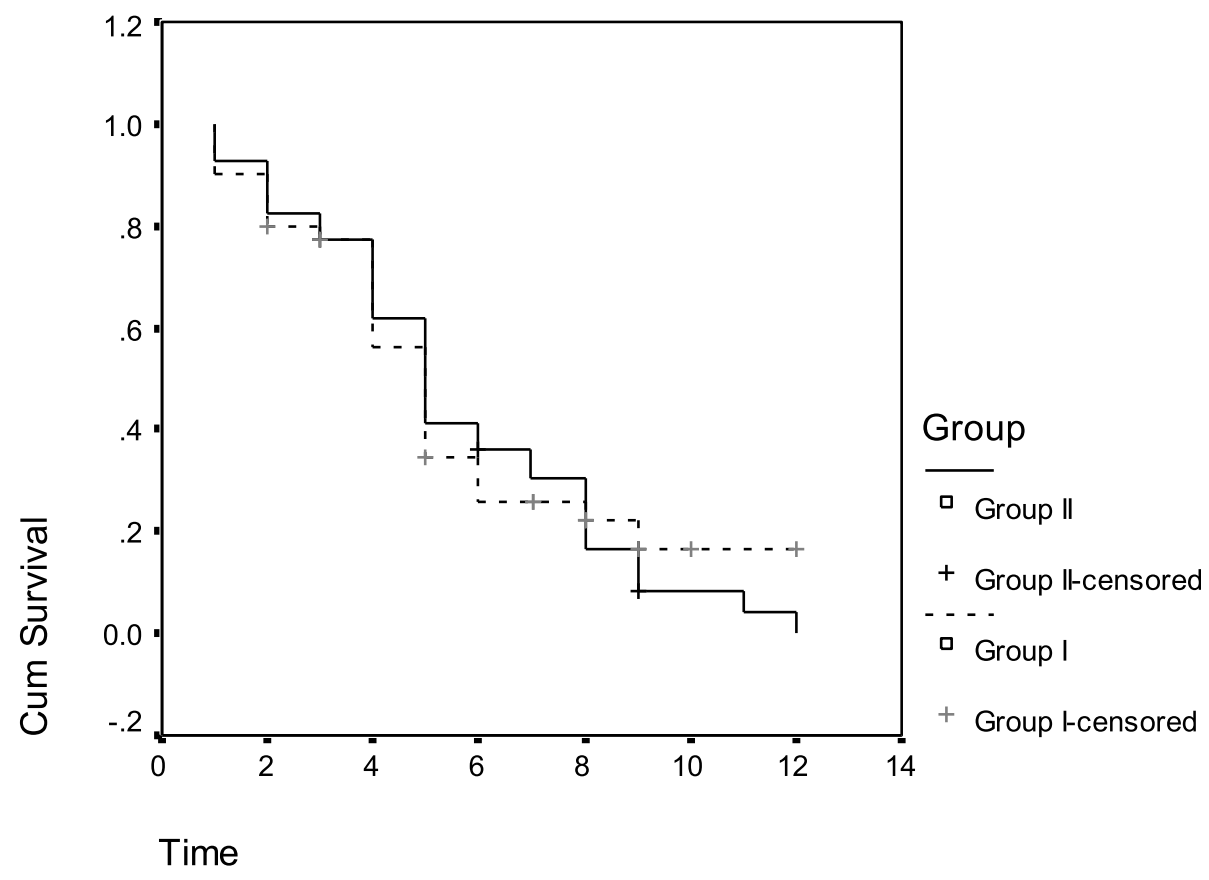

Fig. 1 Survival of the studied groups

related to the existing liver disease including encephalopathy and bleeding episodes. Meanwhile, no significant difference was present in rebleeding rates between the two groups, as 5 cases in group 1 experienced bleeding attacks (12.5\%), compared to 3 cases in group II $(7.5 \%)$ ( $p$-value $0.456)$. A highly significant difference was noted in the incidence of hepatic encephalopathy (HE) between group I $(15 / 40)$ and group II $(0 / 40)(p<0.05)$; however, this effect was not present in multivariate analysis (Table 4). No significant difference was observed in the occurrence of adverse events during the study between the two groups as regards diarrhea (5\% and 10\%) and worsening of ascites (17.5\% and $22.5 \%)$ in groups I and II, respectively; however, myalgia was more frequent in the simvastatin group (5\% in group I and $20 \%$ in group II, $p$-value 0.043 ). Multivariate analysis was performed to test simvastatin's effect and confirmed that only survival was affected and no statistical differences between the 2 groups in other factors

Table 4 Multivariate analysis of the effect of simvastatin in improving the survival

\begin{tabular}{lll}
\hline & Multivariate & \\
\cline { 2 - 3 } & OR $\mathbf{( 9 5 \% ~ C l )}$ & $\boldsymbol{p}$-value \\
\hline Encephalopathy & $0.725(0.352-1.652)$ & 0.998 \\
Survival & $0.136(0.020-0.916)$ & $0.040^{*}$ \\
Myalgia & $5.812(0.658-51.361)$ & 0.113 \\
Child score & $4.419(0.874-22.341)$ & 0.072 \\
\hline
\end{tabular}

like the presence of encephalopathy, myalgia, and Child score of the studied patients (Table 4).

\section{Discussion}

In the current study, there was a significant reduction in the incidence of HE episodes in the simvastatin group (0/40), compared to the control group (15/40), and this is in accordance with the finding of studies which showed survival benefits and improvement in liver functions with simvastatin $[14,15]$. Improvement in PHT, reduction in the incidence of HCC, and delays in hepatic decompensation have been associated with statin therapy among patients with cirrhosis $[15,16]$. In our study, there was no significant difference between the two groups concerning INR, albumin level, total bilirubin, AST, and ALT, and this comes with an agreement with the findings in most of the studies discussing the impact of statins on the liver biochemical profile [17-19]. Statins are known to decrease Rho-kinase activity in activated hepatic stellate cells [11]. Besides, statins have anti-inflammatory, immunomodulatory, and antioxidant properties [12]. Simvastatin is also known to induce Krüppel-like factor 2, which improves liver fibrosis and PHT by increasing nitric oxide bioavailability [13, 14]. Generally, conflicting reports are available in the literature regarding liver function changes with statin use, with an insignificant risk of elevated transaminases [20, 21]. No significant difference was observed in the 
adverse effects noted during the study between the two groups in terms of diarrhea or worsening of ascites; however, there was a significant difference between the two study groups in myalgia, while other studies found no significant difference in adverse effect in the term of diarrhea, ascites, and myalgia noted during the study $[17,18]$. Regarding the survival of patients in the two studied groups, there was a significant difference between them. This agrees with Motzkus-Feagans and his colleague [17] and agrees with a study done using the Veteran Affairs Clinical Case Registry [22]. This study described the effect of statins in cirrhotic HCV patients matched 1:5 with statin non-users, finding fewer decompensation episodes and death in statin users. No differences in comorbidities, metabolic conditions, or hepatic function were reported between the groups. The positive effect of statins in cirrhosis decompensation and mortality persisted at 10 years after adjustment for age, FIB-4 index score, serum level of albumin, model for end-stage liver disease (MELD), and CTP scores [22]. In our study, no significant difference was observed between the two groups as regards variceal rebleeding. This also agrees with the finding of Motzkus-Feagans et al., who proved that rebleeding rates were not different between the treatment and the control [17].

Regarding survival in CTP score A and B patients, there was a significant difference between the two studied groups. At the same time, there was an increased survival in group II patients compared to group I. The same finding was conveyed by Motzkus-Feagans and his colleague, who reported an increased survival in decompensated cirrhotic patients who received simvastatin after variceal bleeding [17]. Similarly, Pollo-Flores and colleagues reported the same findings after evaluating statin use in cirrhotic patients to look for increased mortality or decompensation with a mean follow-up of 36 months, including most cirrhotic patients at an early stage (CTP score A) [23]. They show that statin use was associated with lower mortality and fewer hepatic decompensation episodes in multivariate analysis.

More prolonged administration of simvastatin treatment than placebo for severe PHT was assessed in a blinded randomized controlled trial. Three months of $40 \mathrm{mg}$ simvastatin in 24 patients, most CTP A and B nearly two-thirds with use of NSBB and medium/ large esophageal varices including 30\% with previous variceal bleeding, showed a significant reduction in HVPG with greater effect in patients with previous variceal bleeding and medium/large esophageal varices. Again, no significant increase in adverse events from the use of simvastatin was reported [23]. Regarding survival in Child C patients, no significant difference was observed between the two studied groups, which matches the published data in this regard [17].

The current study has some limitations, such as the relatively small sample size, which could be attributed to our narrow inclusion criteria and the long-term followup required for the participants. Repeating the experiment with a larger sized sample could confirm our findings.

\section{Conclusions}

Adding simvastatin to the standard therapy in secondary prevention of variceal bleeding could be associated with survival benefits in patients with Child A and B cirrhosis, while it was incapable of reducing rebleeding. Further studies are required to confirm this survival benefit.

\section{Abbreviations}

CTP score: Child-turcotte-pugh score; GOVs: Gastroesophageal varices; HCV: Hepatitis C virus; HBV: Hepatitis B virus; MELD: Model for end-stage liver disease; NSBB: Non-selective $\beta$-blockers; PHT: Portal hypertension

\section{Acknowledgements \\ None}

Authors' contributions

The study was designed by HE, HA, and EST. AA and DNE collected the study data and oversaw the participant visits. MEK and RE provided regulatory oversight. DNE, RE, and MEK wrote the first draft of the article. All authors contributed to the reviewing and editing of the article and approved the final version. Article preparation was done by all study authors, and the decision to submit the article for publication was made by all the study authors

Funding

This is a non-funded work

\section{Availability of data and materials}

The datasets used and/or analyzed during the current study are available from the corresponding author on reasonable request.

\section{Declarations}

Ethics approval and consent to participate

All procedures performed in this study involving human participants were following the ethical standards of the institutional and/or national research committee and with the 1964 Helsinki Declaration and its later amendments or comparable ethical standards. The study was approved by the Research Ethics Committee (REC) for human subject research at the National Liver Institute in 2017. Informed consent was obtained from all individual participants included in the study.

Consent for publication

All authors agree to the journal rules for publications.

Competing interests

The authors declare that they have no competing interests.

\section{Author details}

${ }^{1}$ Hepatology and Gastroenterology Department, National Liver Institute, Menoufia University, Menoufia, Egypt. 'Tanta Fever Hospital, Tanta, Gharbiah, Egypt. ${ }^{3}$ Tropical Medicine Department, Faculty of Medicine, Minia University, Minya, Egypt. ${ }^{4}$ Endemic Medicine Department, Faculty of Medicine, Helwan University, Ain Helwan, Cairo 11795, Egypt.

Received: 6 April 2021 Accepted: 30 August 2021

Published online: 12 September 2021

References

1. Bosch J, Abraldes JG, Berzigotti A, García-Pagan JC (2009) The clinical use of HVPG measurements in chronic liver disease. Nat Rev Gastroenterol Hepatol. 6(10):573-582. https://doi.org/10.1038/nrgastro.2009.149 
2. Bosch J, Abraldes JG, Groszmann R (2003) Current management of portal hypertension. J Hepatol. 38(Suppl 1):S54-S68. https://doi.org/10.1016/S01688278(02)00430-0

3. Vargas V, Rimola A, Casanovas T, Castells L, Navasa M, Baliellas C, Bilbao I, Visa J, Jaurrieta E, Margarit C (2003) Applicability of liver transplantation in Catalonia at the end of the millennium. A prospective study of adult patient selection for liver transplantation. Transpl Int. 16(4):270-275. https://doi. org/10.1111/j.1432-2277.2003.tb00298.x

4. Failli P, DeFranco RM, Caligiuri A et al (2000) Nitrovasodilators inhibit platelet-derived growth factor-induced proliferation and migration of activated human hepatic stellate cells. Gastroenterology. 119(2):479-492. https://doi.org/10.1053/gast.2000.9354

5. García-Calderó H, Rodríguez-Vilarrupla A, Gracia-Sancho J, Diví M, Laviña B, Bosch J, García-Pagán JC (2011) Tempol administration, a superoxide dismutase mimetic, reduces hepatic vascular resistance and portal pressure in cirrhotic rats. J Hepatol. 54(4):660-665. https://doi.org/10.1016/j.jhep.2010. 07.034

6. Morales-Ruiz M (2003) Cejudo-martín P, Fernández-Varo G, et al. Transduction of the liver with activated Akt normalizes portal pressure in cirrhotic rats. Gastroenterology. 125(2):522-531. https://doi.org/10.1016/S001 6-5085(03)00909-0

7. de Franchis R (2005) Evolving consensus in portal hypertension report of the Baveno IV Consensus Workshop on methodology of diagnosis and therapy in portal hypertension. J Hepatol. 43(1):167-176. https://doi.org/10.1 016/j.jhep.2005.05.009

8. Blum A, Shamburek R (2009) The pleiotropic effects of statins on endothelia function, vascular inflammation, immunomodulation and thrombogenesis. Atherosclerosis. 203(2):325-330. https://doi.org/10.1016/j.atherosclerosis.2 008.08 .022

9. Trebicka J, Hennenberg M, Laleman W, Shelest N, Biecker E, Schepke M, Nevens F, Sauerbruch T, Heller J (2007) Atorvastatin lowers portal pressure in cirrhotic rats by inhibition of RhoA/Rho-kinase and activation of endothelial nitric oxide synthase. Hepatology. 46(1):242-253. https://doi. org/10.1002/hep.21673

10. Violi F, Calvieri C, Ferro D, Pignatelli P (2013) Statins as antithrombotic drugs. Circulation. 127(2):251-257. https://doi.org/10.1161/CIRCULATIONA HA.112.145334

11. Zafra C, Abraldes JG, Turnes J, Berzigotti A, Fernández M, García-Pagán JC, Rodés J, Bosch J (2004) Simvastatin enhances hepatic nitric oxide production and decreases the hepatic vascular tone in patients with cirrhosis. Gastroenterology. 126(3):749-755. https://doi.org/10.1053/j.gastro.2 003.12 .007

12. Garcia-Pagan J-C, Villanueva C, Albillos A, Banares R, Morillas R, Abraldes JG, Bosch J, on behalf of the Spanish Variceal Bleeding Study Group (2009) Nadolol plus isosorbide mononitrate alone or associated with band ligation in the prevention of recurrent bleeding: a multicentre randomised controlled trial. Gut. 58(8):1144-1150. https://doi.org/10.1136/gut.2008.1712 07

13. Sauerbruch T, Mengel M, Dollinger $M$ et al (2015) Prevention of rebleeding from esophageal varices in patients with cirrhosis receiving small-diameter stents versus hemodynamically controlled medical therapy. Gastroenterology 149(3):660-8. el

14. Abraldes JG, Bureau C, Stefanescu H, Augustin S, Ney M, Blasco H, Procopet B, Bosch J, Genesca J, Berzigotti A, for the Anticipate Investigators (2016) Noninvasive tools and risk of clinically significant portal hypertension and varices in compensated cirrhosis: the "Anticipate" study. Hepatology. 64(6): 2173-2184. https://doi.org/10.1002/hep.28824

15. Singh S, Singh PP, Singh AG, Murad MH, Sanchez W (2013) Statins are associated with a reduced risk of hepatocellular cancer: a systematic review and meta-analysis. Gastroenterology. 144(2):323-332. https://doi.org/10.1 053/j.gastro.2012.10.005

16. Elwan N, Salah R, Hamisa M et al (2018) Evaluation of portal pressure by Doppler ultrasound in patients with cirrhosis before and after simvastatin administration-a randomized controlled trial. F1000Research. 7:256. https:// doi.org/10.12688/f1000research.13915.1

17. Motzkus-Feagans C, Pakyz A, Ratliff S et al (2013) Statin use and infections in Veterans with cirrhosis. Aliment Pharmacol Ther. 38(6):611-618. https://doi. org/10.1111/apt.12430

18. Schuppan D, Afdhal NH (2008) Liver cirrhosis. Lancet. 371(9615):838-851. https://doi.org/10.1016/S0140-6736(08)60383-9
19. Bays H, Cohen DE, Chalasani N, Harrison SA (2014) An assessment by the statin liver safety task force: 2014 update. J Clin Lipidol. 8(3):S47-S57. https://doi.org/10.1016/j.jacl.2014.02.011

20. Russo MW, Hoofnagle JH, Gu J, Fontana RJ, Barnhart H, Kleiner DE, Chalasani $\mathrm{N}$, Bonkovsky HL (2014) Spectrum of statin hepatotoxicity: experience of the drug-induced liver injury network. Hepatology. 60(2):679-686. https://doi. org/10.1002/hep.27157

21. Mohanty A, Tate JP, Garcia-Tsao G (2016) Statins are associated with a decreased risk of decompensation and death in veterans with hepatitis Crelated compensated cirrhosis. Gastroenterology 150(2):430-40. e1

22. Kumar S, Grace ND, Qamar AA (2014) Statin use in patients with cirrhosis: a retrospective cohort study. Dig Dis Sci. 59(8):1958-1965. https://doi.org/10.1 007/s10620-014-3179-2

23. Pollo-Flores P, Soldan M, Santos UC, Kunz DG, Mattos DE, da Silva AC, Marchiori RC, Rezende GFM (2015) Three months of simvastatin therapy vs. placebo for severe portal hypertension in cirrhosis: a randomized controlled trial. Dig Liver Dis. 47(11):957-963. https://doi.org/10.1016/j.dld.2015.07.156

\section{Publisher's Note}

Springer Nature remains neutral with regard to jurisdictional claims in published maps and institutional affiliations.

\section{Submit your manuscript to a SpringerOpen ${ }^{\circ}$ journal and benefit from:}

- Convenient online submission

- Rigorous peer review

- Open access: articles freely available online

- High visibility within the field

- Retaining the copyright to your article

Submit your next manuscript at $>$ springeropen.com 